
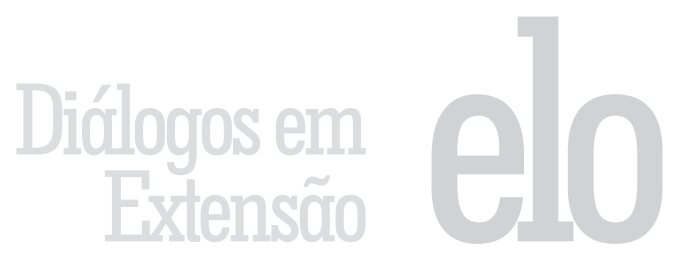

\title{
O ensino da dança: 0 desafio de dançar com o outro
}

Carla Drumond Moreira ${ }^{1}$, Kátia Cupertino ${ }^{2}$

RESUMO: Trata-se de um relato de experiência vivenciado no Projeto "Dançando na Escola" vinculado ao Programa de Extensão da UFMG. Neste projeto objetivou-se oferecer a vivência do ensino da dança contemporânea em uma escola pública de ensino especial. As atividades desenvolvidas deram-se a partir de vivências lúdicas, autônomas e criativas, possibilitando a construção de um dançar próprio e o diálogo entre a sensibilidade e a arte do dançar contemporâneo.

Palavras chave: autonomia, criatividade, dança contemporânea, educação especial.

Áreas temáticas: Educação e cultura. 


\section{Teaching dancing: The challenge of dancing with each other}

ABSTRACT: This is an experience report named "Dancing School" Project linked to the Extension Programme at UFMG. This project aims to offer the experience of teaching contemporary dance in a public special education school. Activities were based on recreational, autonomous and creative experiences allowing a construction of a proper dancing and a dialogue between sensibility and the art of contemporary dance.

Keywords: Autonomy, contemporary dance, creativity, special education.

Thematic areas: Education and culture.

\section{O enseñanza de la danza: El reto de bailar con el otro}

RESUMEN: Se trata de una experiencia vivida em la "Escuela de Baile" Proyecto vinculado al Programa de Extensión de la UFMG. Este proyecto tiene como objetivo oferecer la experiencia de la enseñanza de la danza contemporânea en una escuela de educación pública especial. Las actividades se dieron a partir de experiencias recreativas, autónomas y creativa que permite la construcción de un baile apropiado y un diálogo entre la sensibilidad y el arte de la danza contemporánea.

Palabras clave: Educación especial, la autonomia, la creatividad, la danza contemporânea.

Área temática: Educación e cultura. 


\section{PRIMEIRO PASSO: INTRODUÇÃO}

O curso superior de Educação Física da Universidade Federal de Minas Gerais/ EEFFTO-UFMG possui vários Projetos de Extensão, e um deles é o Projeto denominado "Dançando na Escola" que faz parte do Programa "Dança Experimental: um diálogo entre a dança e a educação". O programa compreende a dança como um conteúdo artístico e cultural que contribui para a educação e formação dos indivíduos considerando seus diferentes contextos sociais, seus corpos e suas histórias de vidas; em uma perspectiva crítica, criativa, autônoma, portanto transformadora, que permite estabelecer o diálogo entre a sensibilidade pelo movimento e a arte de dançar.

Ao entrar para o Programa de Dança Experimental-PRODAEX/ UFMG no ano de 2011, o primeiro interesse foi entender e aprender sobre o processo e a criação da dança contemporânea. Como bolsista do PRODAEX, é necessário participar efetivamente dos três projetos que incorporam este Programa. O Projeto "Dança I" tem como objetivo o estudo, a pesquisa e a problematização de textos escritos sobre dança, ampliando o conhecimento pedagógico e acadêmico pertinentes para o ensino e a criação da dança contemporânea no contexto escolar. Já o Projeto "Dança em Módulos" se estende à comunidade em geral por meio de oficinas de dança ministradas pelos alunos participantes do programa (bolsistas ou voluntários), realizadas na própria EEFFTO/UFMG, com o objetivo de oferecer a experimentação e criação de movimentos que surgem a partir do estímulo, do expressar de sentimentos, ideias e valores nas relações do dançar com outro e consigo mesmo. Por último, o Projeto "Dançando na Escola”, que se objetiva levar para espaços institucionais públicos o ensino da dança contemporânea problematizada no contexto da inclusão de diferentes sujeitos, possibilitando e instigando a criação da dança própria, a partir de sua vivência anterior (ou não) com a dança.

A partir dessa amplitude de tempo e espaço para pensar, refletir, dialogar, debater, criar e construir um novo olhar para o ensino/ aprendizado da dança, fui instigado a oferecer a dança experimental para alunos da educação especial, uma vez que esses sujeitos diferentemente se expressariam através da dança, devido às suas condições motoras e cognitivas. Assim, vi a necessidade de ampliar, pesquisar e aprofundar o conhecimento sobre as possibilidades, limites e superações motoras e cognitivas destes sujeitos, com a proposta de levar a dança para aluno com deficiências físicas e/ou necessidades intelectuais. Nessa direção, o conhecimento interdisciplinar das diversas disciplinas oferecidas pelo curso de educação 
física como, por exemplo, anatomia, cinesiologia, fisiologia humana e do exercício, psicologia, além das teorias da atividade física adaptada e atividade física e doença mental, no que diz respeito à aprendizagem do desenvolvimento motor, cognitivo, psicológico e afetivo, trouxeram maior esclarecimento e segurança sobre esse novo sujeito\corpo no campo da arte da dança. Sobre o assunto, vale tomar como referência

A dança no setor da educação especial deve ser uma prática devidamente planejada para que esteja alcançando não só o senso lúdico e emocional do aluno, e sim para que se forme nele uma ponte ligando as áreas das ciências humanas, exatas e até mesmo tecnológicas, pois a arte de dançar passa perpendicularmente sobre todas supracitadas, oferecendo então ao aluno uma prática salutar ao seu rendimento biopsicossocial (RAMOS, 2010, p.169-170).

Com base nas leituras e reflexões sobre o ensino da dança, compartilhadas com a orientadora do Programa (Kátia Cupertino), tive como referencial teórico o conhecimento das teorias de Rudolf Laban (1978) e seu Sistema de Estudo do Movimento que, hoje em dia, pode ser utilizado como base de estudo em qualquer estilo de dança; o entendimento da proposta de Izabel Marques (1997), ao defender a dança no espaço escolar levando-se em consideração o contexto histórico vivido pelo aluno e suas relações com a reflexão e criação da dança a partir do dançar no mundo; além das teorias e reflexões da pedagogia do sujeito propostas por Paulo Freire (1967), instigando um processo de ensino aprendizagem pela autonomia em busca da cidadania.

\section{SEGUNDO PASSO: OUTROS CORPOS EM OUTRO ESPAÇO}

O Projeto "Dançando na Escola" acontece na Escola Municipal de Ensino Especial de Venda Nova em um bairro de periferia de Belo Horizonte. Atualmente o Projeto é desenvolvido em apenas um turno. Nesse, há 35 alunos com faixa etária entre 14 e 45 anos. Todos os alunos possuem deficiências físicas e/ou necessidades intelectuais, sendo diagnosticado entre autismo, deficiência auditiva, déficit intelectual, paralisia cerebral, dentre outras.

Inicialmente observei os alunos em seu ambiente escolar e nas suas atividades cotidianas. Na escola há a diferenciação entre os que são mais debilitados, ou seja, os que apresentam maior dificuldade em relação à realização das tarefas e rotinas da escola e os que 
possuem menos dificuldade para a realização destas tarefas, portanto, são mais autônomos.

Dentro da rotina da escola, os alunos contam com aulas de jardinagem, culinária, artes, educação física, capoeira, dentre outras. No entanto, não possuem outras disciplinas curriculares existentes no sistema regular de ensino, como a matemática e o português, por exemplo.

Trabalhei em um espaço privilegiado na escola, um auditório com equipamento de som, vídeo, cadeiras e um amplo palco com acesso para os alunos que possuem mobilidade reduzida. Este ambiente facilitou bastante o meu trabalho, pois além do amplo salão para os deslocamentos nas atividades de dança, podia-se também trabalhar com o uso de vídeos sem ter que deslocar os alunos para outros lugares.

\section{TERCEIRO PASSO: O DESAFIO}

Nas primeiras semanas deparei-me com a primeira questão, a de como separar a turma. Eu tinha dois horários, portanto disponibilidade para atender duas turmas. A direção, embora tivesse me dado autonomia para distribuir os alunos, já havia me informado que uma parte deles possuía muitas dificuldades e a outra era de alunos "bastante adaptáveis". Assim, decidi dividi-los por semelhança em seus diagnósticos, configurando a primeira turma bem mais comprometida e, a segunda bem mais receptiva às atividades propostas nas aulas de dança.

Para minha surpresa, o resultado desta divisão não foi a melhor solução, pois as atividades propostas não foram bem compreendidas por eles. A partir daí percebi que a solução viria com a coeducação, ou seja, os alunos menos comprometidos ajudariam aos mais debilitados. O resultado foi bastante positivo, pois os alunos que possuíam menos dificuldades auxiliaram com bastante interesse e motivação no andamento das aulas e também no processo de criação. Essa turma mais "proativa" tornou-se importante no processo de ensino- aprendizagem dos demais ao colaborar de igual para igual com os colegas, tornando uma peça chave para o entendimento e sucesso das atividades propostas por mim.

Ao longo do processo, contei também com o auxílio dos monitores e dos demais professores, para reconhecer e redistribuir os alunos por afinidade, ao separá-los nas turmas adequadamente. Este fator se justificou por perceber que, ao formar as turmas por afinidade (ou não) entre eles, isso também favorecera o sucesso das aulas, pois muitos deles se desentendiam e não aceitavam certo colega. 
Nas primeiras aulas, a presença de dois monitores foi de grande importância, auxiliando no deslocamento dos alunos para o local das aulas de dança, ao utilizarem cadeiras de rodas e aos que possuíam maiores dificuldades de locomoção. Essa ajuda tornou mais eficiente a assistência aos alunos, pois eu não precisava parar as aulas para ajudar aos que necessitavam de ajuda para as suas necessidades fisiológicas.

\section{QUARTO PASSO: O DANÇAR, OS SENTIDOS}

Inicialmente, nas primeiras aulas, procurei explorar a musicalidade e os movimentos básicos da dança, como andar se deslocando pelo espaço movimentando as partes do corpo, mover-se tentando se expressar conforme a melodia da música sugeria e também "dançar" coletivamente e de forma livre. Porém, percebi que muitos alunos estavam desatentos às atividades propostas, pois muitos não interagiram com as propostas da aula. Quando a aula acabou, pensei em como poderia prender a atenção destes alunos e tornar a aula mais atrativa e lúdica, possibilitando um maior estímulo para a criatividade e o aprendizado da dança. Assim, planejei algumas aulas com o uso de materiais cênicos (fitas, tecidos, vassoura e bolinha de sabão) e também com a utilização de tecidos coloridos, instigando-os a explorarem o corpo e os movimentos em sintonia com os materiais utilizados.

Como recurso didático (instigando a visão), contei com a apresentação de pequenos trechos de vídeos-dança, sendo que alguns vídeos demonstravam materiais se movendo no ritmo de determinada melodia. Assim, após apresentar um vídeo em que se mostrava um tecido movendo-se sob o vento vindo de um ventilador, desenvolvi com os alunos uma aula com o mesmo tecido, cor e textura, além do vento para que os mesmos reproduzissem, de acordo com suas possibilidades de movimento do que viram. O resultado não poderia ser melhor, eles conseguiram associar o vídeo com o tecido que estava em suas mãos. A criatividade e a expressividade afloraram na aula. A partir disso, explorei (instigando a sensibilidade do tato) o esvoaçar do tecido e o dançar, o sentir o tecido passando pelo corpo e movimentar esse tecido em duplas. Assim, todas as aulas foram exploradas com o uso de materiais e em certos dias, o uso de vídeos relacionados ao tema proposto no dia.

Planejei uma aula com fitas de cetim a serem manuseadas ao ritmo de músicas de "batidas eletrônicas", uma vez que havia muitos jovens na sala, associando o que eles gostavam de ouvir no seu cotidiano fora da escola. Como as fitas exercem um grande apelo visual, através de sua plasticidade de movimento no espaço, foram bastan- 
te desenvolvidos os movimentos de braços e de tronco, o que para muitos foi um grande desafio. A aula foi bastante animada, alegre e lúdica, e o deslocamento/reconhecimento do e pelo espaço foram mais bem explorados.

Os alunos menos debilitados pediram muito para que eu ensinasse o forró e apesar de não ter no meu planejamento esse estilo de dança passei a considerar a possibilidade de também trabalhar este ritmo nas aulas, uma vez que fazia parte do contexto do dançar em que eles se inseriam, além da possibilidade de contribuir para a socialização entre os mesmos ao dançarem aos pares. Porém, a turma tinha um maior número de alunos homens e eles não queriam dançar com outros alunos do mesmo gênero ou com alunas que não simpatizavam. Considerei a possibilidade de inserir o forró a partir da "dinâmica da dança da vassoura". Nessa atividade a vassoura vai passando de aluno para aluno, e o aluno que está com a vassoura deve ir ao centro da roda e dançar o "seu" forró. Assim, mais uma vez, a utilização de objetos ajudou no processo de criação e expressão para a dança.

Utilizei também de bolhas de sabão, como um momento de relaxamento, onde os alunos deveriam ouvir as músicas de ritmos mais lentos, e tentar tocar nas bolhas que estavam a voar pelo ar. Todos quiseram participar dessa atividade e esse foi um dos momentos mais interessantes e belos das aulas compartilhadas.

Quanto às novas músicas apresentadas nas aulas (instigando a audição), os alunos mostravam-se bastante motivados, pois a maioria das músicas fazia parte de um vasto repertório de ritmos e sons diferentes dos que eram "acostumados" a ouvir. Isso foi também um dos motivos para instigar a curiosidade e a expressividade, desvinculada dos movimentos pré-fabricados pelo mercado midiático. Ao acompanhar os ritmos, eles amavam bater palmas e pés com músicas que estimulam a sonoridade e as dinâmicas rítmicas. Adoravam esvoaçar os tecidos com músicas que reproduziam os sons da natureza. A partir disso meu trabalho e até a minha motivação melhoraram.

Entendi que tudo que se pretende levar para os alunos de ensino especial deve ser pesquisado e estudado anteriormente, para avaliar se é possível fazer, criar e apreender; por isso houve a necessidade constante de se ter vários planejamentos, para o caso de um "não dar certo". Ao planejar, pensava-se sempre no inesperado, e isto era um desafio constante, porém extremamente instigante. A cada aula tudo era debatido, refletido e pensado juntamente com os colegas e a orientadora do Programa do PRODAEX. 


\section{QUINTO PASSO: ALGUMAS DIFICULDADES... PORÉM, NOVOS OLHARES}

Conhecer os diagnósticos dos alunos auxiliou-me no sentido de elaborar as atividades pensando na diversidade de corpos, limites e potencialidades. Conhecer suas patologias, síndromes ou transtornos ajudou-me a tratar as aulas no sentido da relação aluno-professor e na apresentação das atividades. No entanto, trabalhar especificamente cada necessidade de cada aluno não foi possível de se realizar, até por que esse não era o objetivo, além dos alunos estarem agrupados independentemente de suas deficiências intelectuais ou físicas.

\section{MAIS UM PASSO, NÃO O ÚLTIMO: ALGUMAS CONSIDERAÇÕES}

O custeio para o investimento dos recursos materiais (CDs, vídeos e objetos cênicos) foi primordial para que as aulas tivessem sucesso; ao contrário, não teria conseguido desenvolver meu trabalho de forma eficiente. Percebe-se assim que o investimento realizado por mim a partir da bolsa de extensão contribuiu para oferecer e obter uma aula de qualidade. No caso, pensa-se na possibilidade de serem pleiteados pelo Programa do PRODAEX os recursos materiais necessários para a implementação desse projeto sem onerar o bolsista, além de possibilitar a ampliação de levá-lo a outros espaços de ensino.

A partir das aulas vivenciadas neste espaço especial de pessoas diferentemente potenciais, concluí que a dança experimental proposta pelo PRODAEX é possível ser levada em qualquer espaço e tempo, uma vez que o sujeito é instigado a dançar e criar a sua própria dança, pois o mais importante é se (re) conhecer capaz de atuar como um protagonista no mundo em que vive. Neste contexto, tornou-se possível estabelecer uma conexão com as suas histórias de vida e o mundo à sua volta, numa possibilidade de transformá-lo pela sensibilidade.

Conclui-se também que é possível oferecer a dança de forma lúdica, interativa e criativa, contribuindo para uma melhor motivação, sensibilização, socialização e liberdade de movimentos pelos alunos do ensino especial, ao instigá-los a (re) conhecerem seus corpos não só pelas limitações, mas, sobretudo, pela potencialidade a partir das diferentes formas de dançar, criar e se expressar, enfim, de se tornar autônomos na sua expressividade. As aulas resultaram no interesse da dança pelos alunos que, na sua grande maioria nunca havia dançado, mostrando que é possível o aprendizado e, sobretudo, a vivência da arte pela dança. 

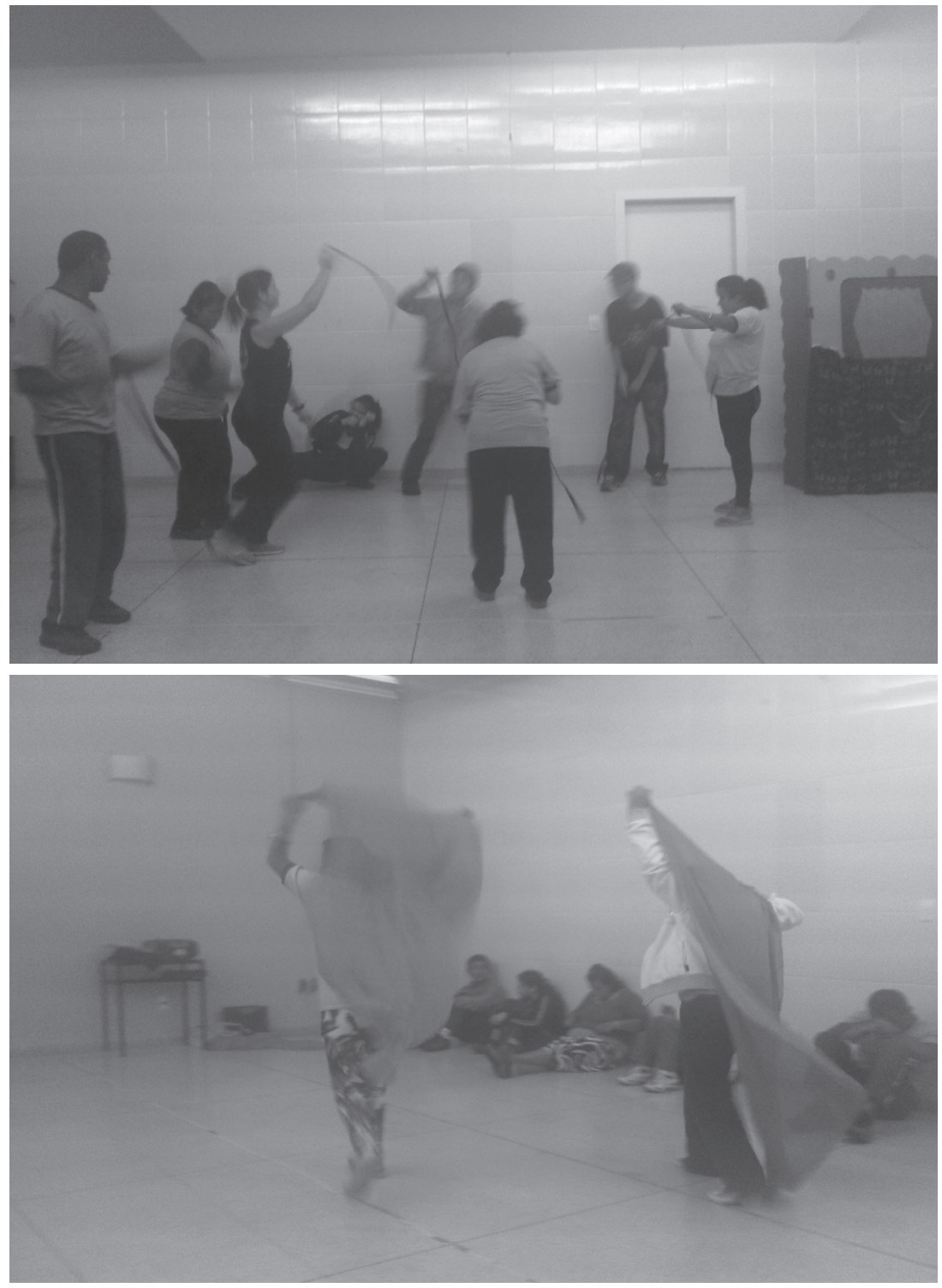

A oportunidade de participar de um Projeto de Extensão Universitária contribuiu muito para minha formação como professora, dançarina e pesquisadora, ampliando os meus conhecimentos no campo da educação, da dança e da educação física e a sua interlocução multidisciplinar.

Desafio foi a palavra com a qual convivi desde o primeiro ao último dia de trabalho na educação especial. Falar que foi fácil não condiz muito com a verdade que vivi, mas a alegria e a satisfação 
que senti ao vir os alunos dançarem, sorrindo alegremente, compensaram qualquer dificuldade que passei. Avaliá-los e perceber o desenvolvimento de cada um fez-me rever conceitos e apaixonar-me pela turma e principalmente pela educação especial. Se formos desistir na primeira dificuldade que encontrarmos nos afazeres da vida, não iremos aprender nada.

O pensamento inicial de ser possível ensinar a dançar para jovens e adultos com corpos "diferentes" foi revertido em aprender com os diferentes! Nesse processo de ensino da dança vi que aprender com o outro foi o que levei de mais precioso; parafraseando Cora Coralina (1983, p.136), "Feliz aquele que transfere o que sabe e aprende o que ensina".

\section{REFERÊNCIAS BIBLIOGRÁFICAS}

CORALINA, C. Vintém de cobre: meias confissões de Aninha. Goiás: UFG Editora, 1983. 136p.

FREIRE, P. Educação como prática da liberdade. Rio de Janeiro: Paz e Terra, 1967.

LABAN, R. Domínio do movimento. São Paulo: Summus, 1978.

MARQUES, I.A. Dançando na escola. Motriz, São Paulo v.3, n.1, p.20-28, jun. 1997.

RAMOS, É.S. O ensino da dança na educação especial sob a perspectiva interdisciplinar. Revista Eletrônica Aboré, p.169-170, dez. 2010. Disponível em http:// www.revistas.uea.edu.br/old/abore/artigos/artigos_4/162.pdf. Acesso em: 25 out.2012. 